\title{
INVESTIGAÇÃO DE DOIS EDIFÍCIOS DE OSCAR NIEMEYER: MODELAGEM PARAMÉTRICA E FABRICAÇÃO DIGITAL ${ }^{1}$
}

\author{
STUDY ON TWO BUILDINGS OF OSCAR NIEMEYER: PARAMETRIC \\ MODELING AND DIGITAL PRODUCTION
}

\author{
Breno Tisi Mendes da Veiga \\ Universidade Presbiteriana Mackenzie (UPM) \\ brenoveiga@hotmail.com \\ Wilson Florio \\ Universidade Presbiteriana Mackenzie (UPM) / Universidade Estadual de Campinas (UNICAMP) \\ wflorio@uol.com.br
}

\begin{abstract}
Resumo
Este artigo analisa dois projetos curvilíneos do arquiteto Oscar Niemeyer, ambos na cidade de São Paulo e produzidos na década de 1980: o Auditório Simón Bolivar e o Salão de Atos Tiradentes, no complexo do Memorial da América Latina. O objetivo da pesquisa é investigar a geometria dos elementos arquitetônicos, através da modelagem paramétrica e da fabricação digital.
\end{abstract}

Palavras-chave: Oscar Niemeyer. Fabricação Digital. Modelagem Paramétrica.

\begin{abstract}
This article analyzes two curvilinear designs of the architect Oscar Niemeyer, both in the city of São Paulo and produced in the 1980s: the Simón Bolivar Auditorium and the Hall of Acts Tiradentes, in the complex of the Memorial of Latin America. The goal of the research is to investigate the geometry of architectural elements through parametric modeling and digital production.
\end{abstract}

Keywords: Oscar Niemeyer. Digital Production. Parametric Modeling.

\section{INTRODUÇÃO}

Este artigo tem como objetos de estudo dois projetos curvilíneos do arquiteto Oscar Niemeyer, ambos na cidade de São Paulo e produzidos na década de 1980: o Auditório Simón Bolivar e o Salão de Atos Tiradentes, no complexo do Memorial da América Latina. O objetivo da pesquisa é investigar a geometria dos elementos arquitetônicos, através do uso da modelagem paramétrica (MP) e fabricação digital (FD).

Niemeyer era fascinado por formas que fugiam da produção de caráter funcionalista, importado da Europa. Criticava os "puristas" que projetavam a partir de uma malha estrutural ortogonal, privilegiando estrutura à estética. No Memorial da América Latina, Niemeyer projetou um elaborado conjunto de curvas que se desenvolvem a partir de arcos de circunferências, tangentes e segmentos de reta.

\footnotetext{
1 VEIGA, B. T. M.; FLORIO, W. Investigação de dois edifícios de Oscar Niemeyer: Modelagem paramétrica e Fabricação digital. In: ENCONTRO BRASILEIRO DE TECNOLOGIA DE INFORMAÇÃO E COMUNICAÇÃO NA CONSTRUÇÃO, 7., 2015, Recife. Anais... Porto Alegre: ANTAC, 2015.
} 
Parâmetro é uma variável numérica que, quando alterada, muda o resultado final de uma equação ou potencialmente uma geometria. A grande vantagem de projetar ou analisar um edifício a partir de parâmetros, pelo processo de modelagem paramétrica (MP) é a habilidade de se criar variadas versões para um mesmo partido. É possível criar uma família de formas que compartilham uma relação de semelhança entre si, topologicamente são similares, mas apresentam diferentes formas.

Para este artigo foram analisados, por meio da manipulação de parâmetros das dimensões, o Auditório Simón Bolivar e o Salão de Atos Tiradentes, com ênfase na plasticidade dos edifícios e nas relações de proporção, ritmo e harmonia. Com a MP foi possível investigar diferentes relações entre os vários parâmetros do projeto. A pesquisa também teve a intenção de contrapor o projeto construído com as demais opções e discutir o porquê da forma escolhida pelo arquiteto. É possível entender como a experimentação de diferentes habilidades incita o raciocínio lógico do arquiteto, consequentemente este processo pode ser altamente criativo.

O dinamismo investigativo é propiciado pela MP. A fabricação de protótipos físicos auxilia no desenvolvimento de uma série de modelos tangíveis que facilitam a compreensão da forma e relações espaciais. O manuseio de um modelo físico proporciona um melhor entendimento da tectônica e das diferentes relações espaciais, ajudando o arquiteto a concretizar seu pensamento arquitetônico e chegar a uma solução projetual (SASS; OXMAN, 2006).

Sass (2000) reconstrói por meio da modelagem computacional e da FD dois projetos de Palladio e conclui que a partir da interação entre os dois métodos digitais usados foi possível encontrar a geometria geradora de elementos arquitetônicos nos projetos analisados.

Recentes pesquisas publicadas por: Bruscato e Alvarado, (2010); Bueno e Barrera, (2008); Celani, (2009); Chiarella, (2004); Florio e Tagliari, (2008); Hanna e Turner, (2006); Hernandez, (2004); Herrera, (2009); Tagliari e Florio, (2009) apontam uma crescente importância dos sistemas generativos na arquitetura, e demonstram que o uso da FD e de protótipos tem aumentado o interesse da investigação da tectônica projetual a materialização de modelos computacionais.

Nesta pesquisa os projetos foram modelados seguindo as medidas dos projetos executivos, e com o apoio do software Rhinoceros, auxiliado por plug-ins de parametrização, como o Grasshopper. Nesta etapa novas formas e novas relações espaciais dos edifícios foram buscadas usando a ferramenta Galapagos, que para esta investigação foi utilizada como método de criação de novas formas e novas geometrias.

A alternância entre parâmetros permitiu um melhor entendimento da forma e da geometria dos edifícios analisados. O processo de buscar novas relações geométricas por meio da modelagem paramétrica propiciou um confrontamento entre a forma escolhida e projetada por Oscar Niemeyer e as possíveis alternativas geométricas.

Este artigo está estruturado em quatro partes: i) a modelagem paramétrica dos dois edifícios, analisando as diferentes proporções das dimensões; ii) a fabricação digital dos edifícios por diferentes métodos de fabricação; iii) uma análise geométrica da forma dos edifícios, e iv) uma discussão dos resultados.

\section{MODELAGEM PARAMÉTRICA}

Para Hudson (2010), projeto paramétrico é um processo descrito para a solução de um problema que envolva o uso de variáveis numéricas. Na MP não se procura apenas uma única forma final, mas sim uma família, um conjunto de alternativas para a seleção da mais adequada. 
A arquitetura na era digital visa a customização e a automatização de diversas tipologias nos espaços, se apropriando, segundo Oxman (2006) de quatro elementos principais: i) a representação, que está relacionada às mídias representativas, software; ii) a generação, que inclui o processo generativo de formas; iii) a avaliação, que inclui a avaliação dos processos generativos, e iv) a performance, determinada pelo desempenho e potencialidades integrados. $\mathrm{Na}$ arquitetura digital, a capacidade de gerar novos projetos depende das habilidades perceptuais e cognitivas do arquiteto, pois esse gera um processo contínuo e dinâmico que irá gerar a forma, feita através da simultânea interpretação e manipulação dos processos construtivos computacionais. É a habilidade de "achar uma forma" através de um processo dinâmico e não linear (KOLAREVIC, 2003).

Segundo Woodbury (2010), a MP é dividida em três etapas: a primeira é a organização em sequência dos parâmetros e suas propriedades numéricas, a segunda é a propagação, como o conjunto de parâmetros e componentes são interpretados pela informação e a terceira é a visualização da informação em dados volumétricos em três dimensões.

A modelagem de um objeto paramétrico envolve uma definição prévia de alguns elementos estruturantes do projeto que se inter-relacionam e que possam ser manipulados por meio da MP. Um projeto paramétrico envolve a criação de múltiplas soluções derivadas de uma única fonte e criadas por meio da exploração de parâmetros. Conforme David Rogers, "[...] curvas e superfícies são representadas matematicamente, ou explicitamente, ou implicitamente, ou ainda parametricamente" (ROGERS, 2001, p.2).

Para Schumacher (2011) a modificação quantitativa de parâmetros impulsiona uma mudança qualitativa na busca da forma final. Segundo o autor sempre haverá mais espaço para o aprimoramento da forma arquitetônica quando houver uma maior variabilidade nos valores dos parâmetros que controlam a forma arquitetônica.

Uma adaptação de elementos é atingida através de transformações sobre a forma de projetos pré-estabelecidos. A forma do objeto muda, porém sua integridade topológica não é alterada, isto é, se cria um projeto, uma nova forma, com uma relação de similaridade com formatos desenvolvidos a priori.

Um algoritmo é um procedimento computacional criado para solucionar um problema usando um número de etapas. Segundo Terzidis (2006), é um processo que envolve dedução, indução, abstração, generalização e uma estrutura lógica, é a sistematização de princípios e o desenvolvimento de um plano genérico de solução para um problema. Segundo o autor, o poder dos algoritmos está na habilidade de expandir os limites do intelecto humano.

A análise digital da forma dos edifícios estudados se iniciou com a modelagem paramétrica com o auxílio do plugin Grasshopper. Como é possível observar na Figura 1, as etapas dessa modelagem dependeram da interpretação da geometria dos edifícios. A partir do estudo dos desenhos executivos foi possível interpretar a geometria dos arcos de circunferência e de suas tangentes. O algoritmo construído no Grasshopper na Figura 2 dependeu de parâmetros tais como raios, posição dos arcos e dimensões de cada elemento construtivo. 


\section{TIC2015}

Figura 1- Sequência de etapas de modelagem paramétrica dos principais elementos construtivos do Auditório Simón Bolivar

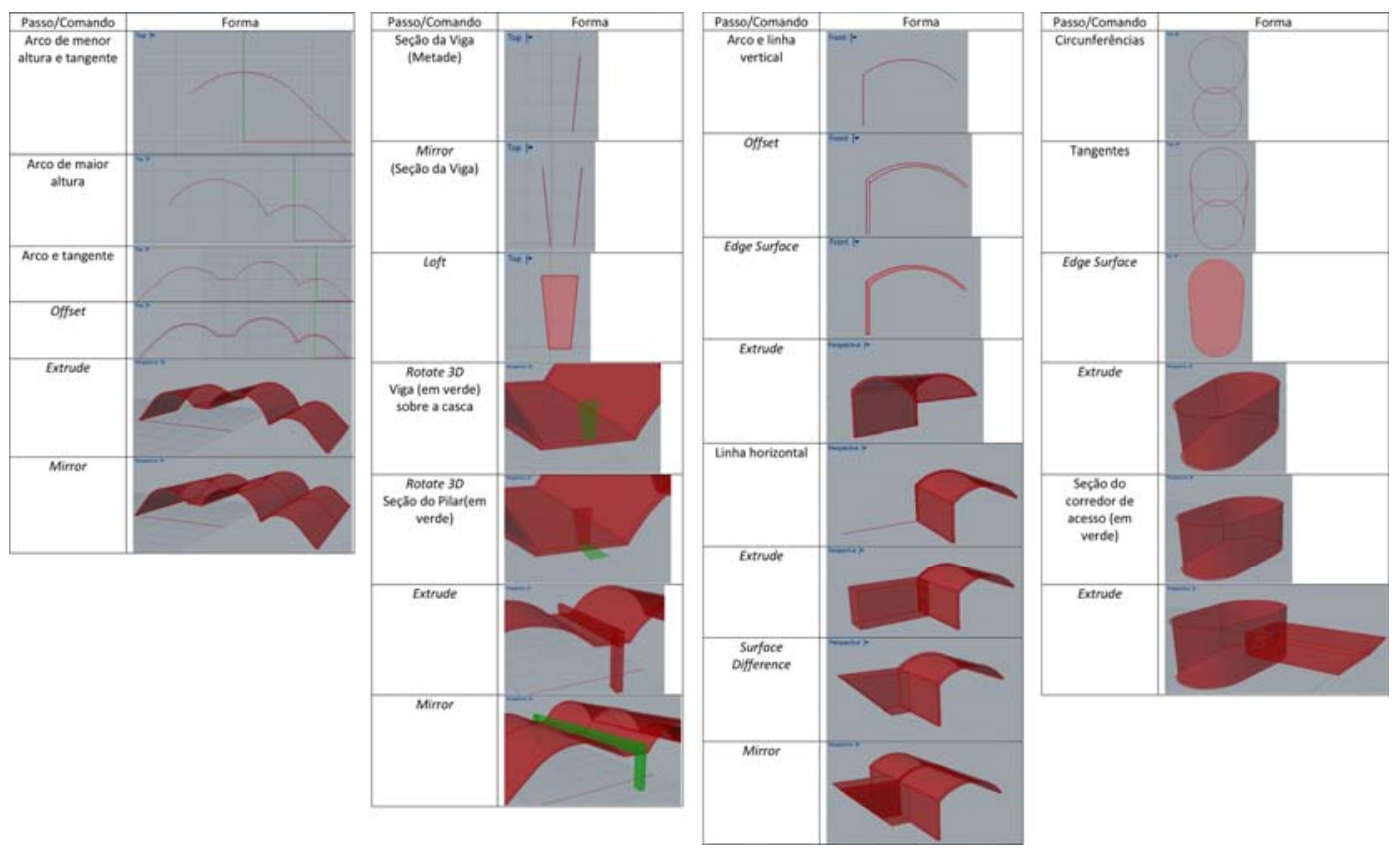

Fonte: Veiga e Florio, 2015

Figura 2 - Algoritmo do Auditório Simón Bolivar

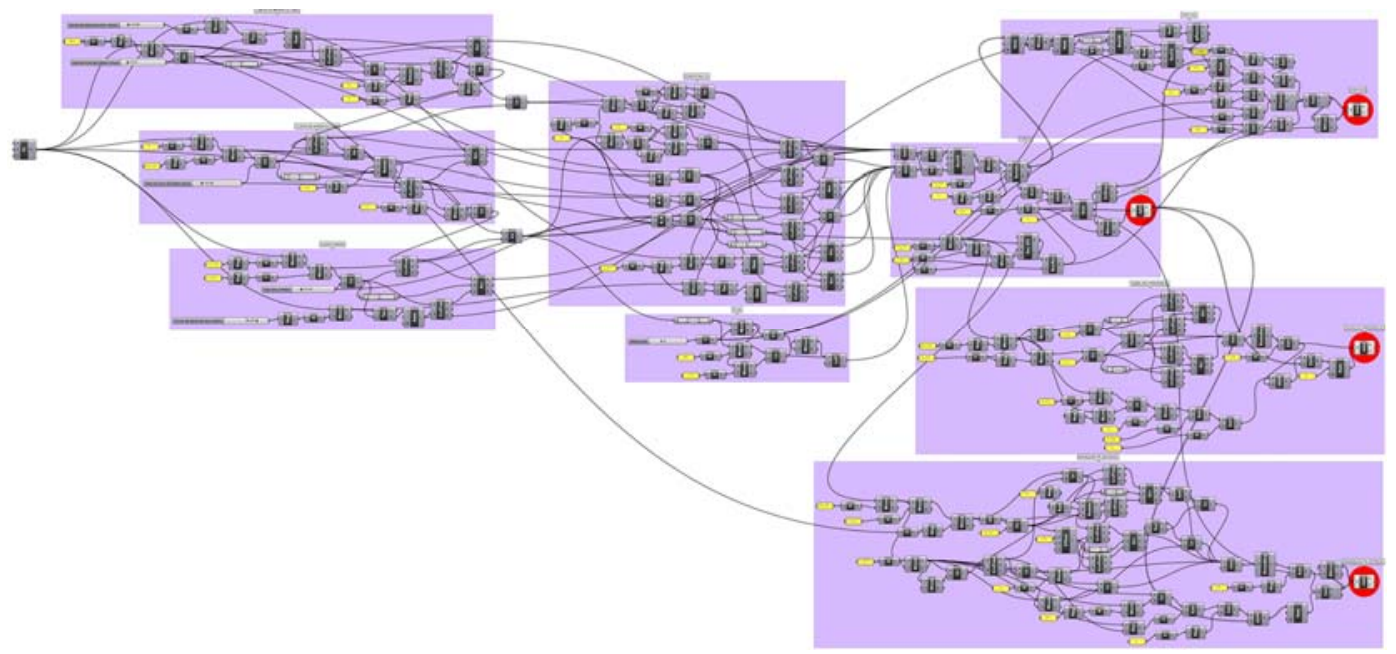

Fonte: Veiga e Florio, 2015

Monedero (2000) afirma que em um projeto paramétrico o que realmente importa é o uso das relações entre os diferentes parâmetros que compõem a forma. Nesta investigação foi usada a ferramenta Galapagos de modo a possibilitar a geração de diferentes formas. Ao investigar diferentes relações espaciais da forma foi possível analisar a plasticidade do edifício, as relações de proporção, simetria e espacialidade. O comando foi usado para encontrar diferentes relações espaciais, como é possível observar na Figura 3. 
Figura 3 - Variações paramétricas realizadas com Galapagos da cobertura do Auditório Simón Bolivar

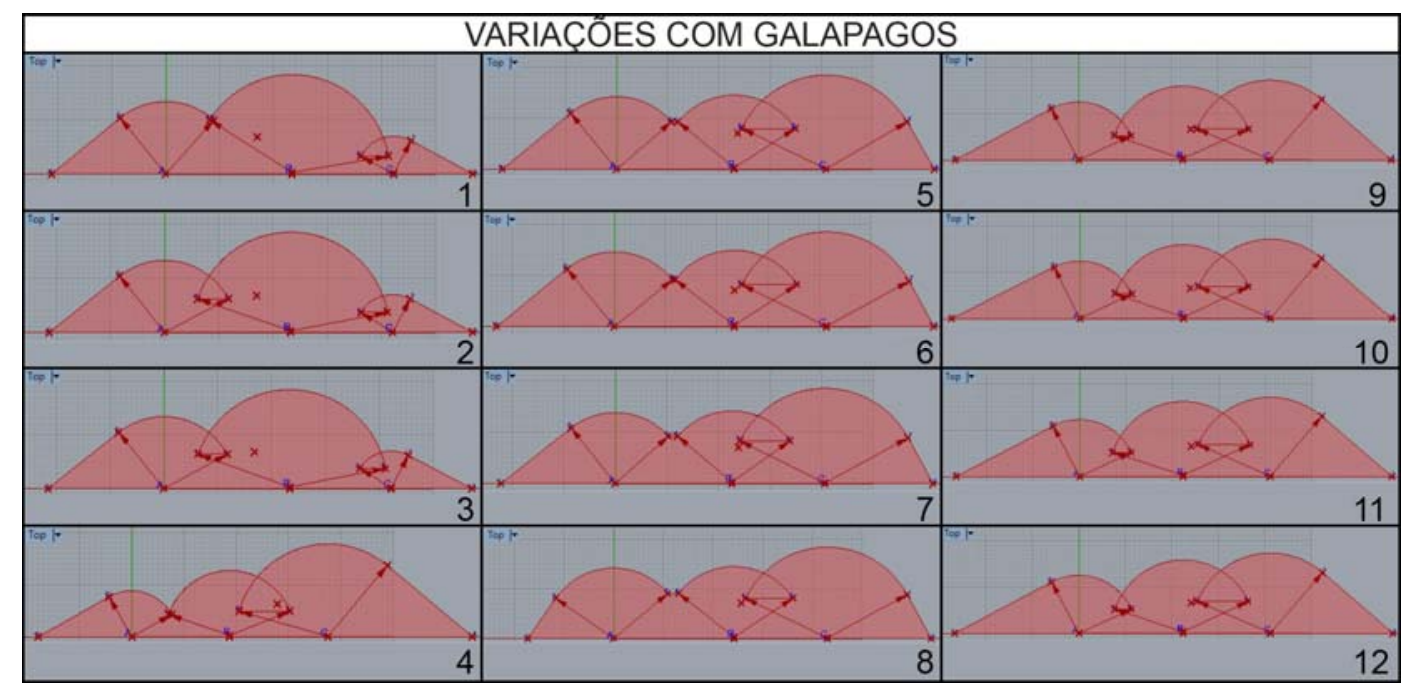

Fonte: Veiga e Florio, 2015

A Figura 3 representa a combinação entre parâmetros e suas variações. Nesta investigação, foi considerada a área da fachada do Auditório; a coluna central mostra variações sobre a área da fachada do auditório, presente nos desenhos executivos, em torno de $1045 \mathrm{~m}^{2}$. Nas duas outras colunas, a primeira e a terceira, a área foi alterada: a primeira coluna (1-4) mostra variações sobre uma área menor do que a construída, $845 \mathrm{~m}^{2}$; a terceira coluna (912) mostra variações de parâmetros sobre uma área maior do que o projeto executivo, 1245 $\mathrm{m}^{2}$.

À primeira vista é possível observar que certas combinações não resultam em formas dotadas de proporção, ritmo e harmonia entre elas. É possível notar que o mesmo princípio pode resultar em formas e espaços pouco coerentes, tanto do ponto de vista arquitetônico, como do ponto de vista de construção.

O estudo com Galapagos se tornou possível a partir de uma forma inicial e uma série de regras implicitas no próprio algoritmo criado no Grasshopper. A MP e a FD são proponderantemente utilizados na concepção de projetos em engenharia e arquitetura, na atualidade, contudo nesta pesquisa nos apropriamos de tais técnicas com a finalidade de análise.

\section{FABRICAÇÃO DIGITAL}

Os processos de FD se dividem em quatro grupos principais, segundo Kolarevic (2003): i) método subtrativo, que funciona pela remoção de material com o auxílio de máquinas por controle numérico (CNC); ii) por método aditivo, que funciona pelo depósito de camadas de material, que pode ser tanto resina quanto um polímero como ABS ou PLA por uma impressora 3D; iii) fabricação 2D, usando cortadoras a laser, cortadoras a plasma, jato d'água ou plotadoras de recorte; e iv) fabricação formativa. De um modo geral, pode se afirmar que nas últimas décadas essas tecnologias têm auxiliado a fabricação de formas orgânicas e incentivado a criatividade.

Há outros autores que definem a FD de modo levemente diferente. Schodek, et al (2005) define que a fabricação 2D é uma subclasse dos professos subtrativos, enquanto que Pottman, et al (2007) estabelece classificações de acordo coma geometria do elemento a ser fabricado. 
O advento de novas tecnologias possibilitam a criação de novas formas, mais complexas, que demandariam muita habilidade, paciência e destreza caso fossem fabricados por métodos manuais, além de possibilitar a percepção do espaço pelo toque físico.

Figura 4 - Fabricação e cortadora a laser do modelo físico do Auditório Simón Bolivar

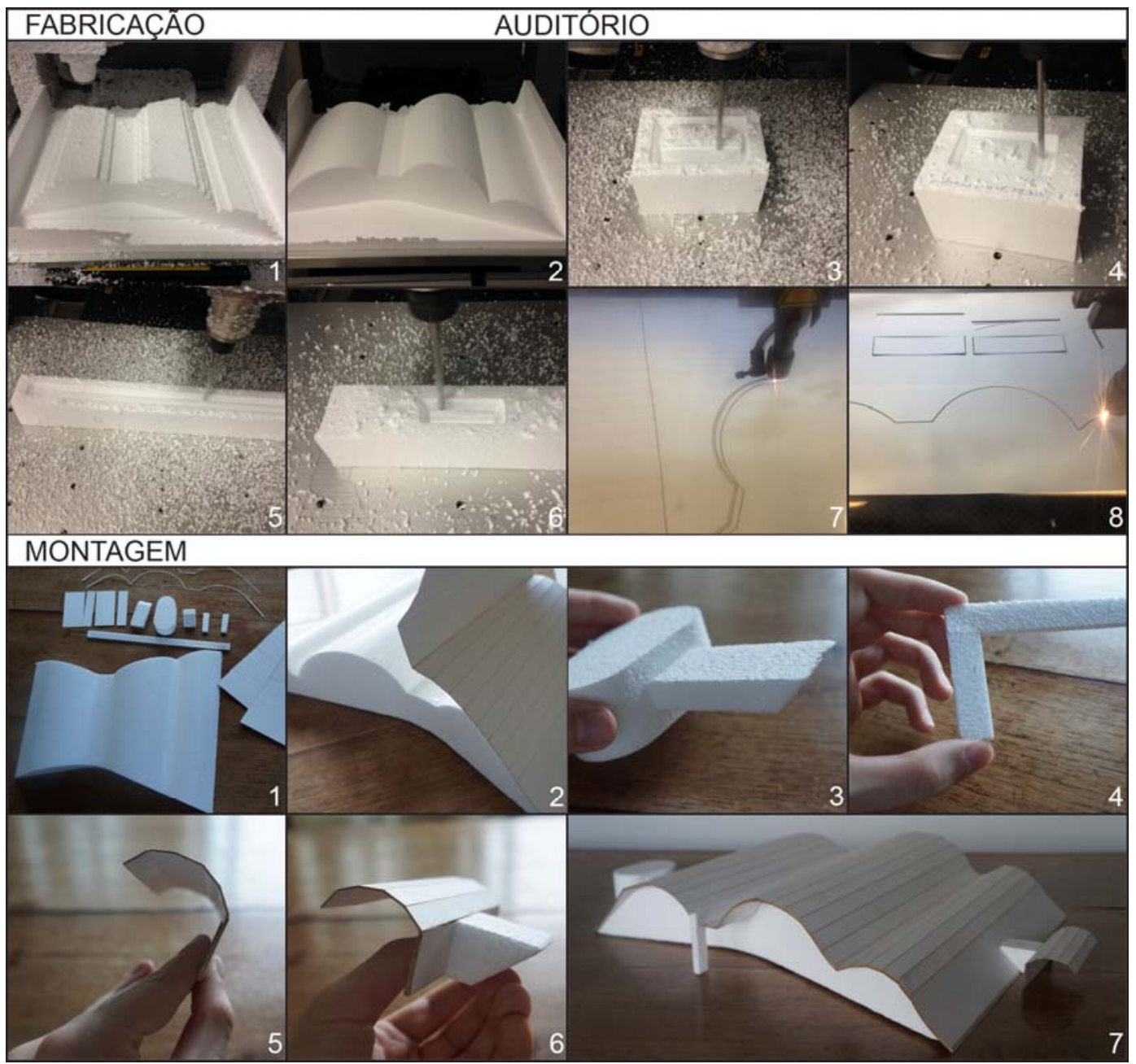

Fonte: Veiga e Florio, 2015

A Figura 4 mostra o processo de fabricação digital do Auditório Simón Bolivar. Para a fabricação do modelo físico foi utilizada uma máquina fresadora modelo MDX-540 da fabricante Roland. É uma fresadora de três eixos ( $x, y$ e $z$ ) capaz de modelar metais, resinas, madeiras e plásticos em uma área de $500 \mathrm{~mm}(\mathrm{X})$ x $400 \mathrm{~mm}(\mathrm{Y}) \times 155 \mathrm{~mm}(\mathrm{Z})$. Possui uma resolução mecânica de $0,001 \mathrm{~mm}$, e é compatível com ferramentas de até $110 \mathrm{~mm}$ de comprimento com uma rotação máxima de 12000 rpm.

A fabricação se dividiu em duas partes: i) a fabricação utilizando a fresadora para produzir os pilares, viga e corpo central do projeto; ii) a fabricação com a cortadora a laser da casca de concreto. Essa divisão ocorreu por causa de uma restrição da máquina fresadora, que se limita a remover material verticalmente.

Ferramentas CNC podem facilitar a fabricação de diferentes tipos de encaixes entre peças de madeira delgadas ou perfis metálicos, a fim de obter diferentes alternativas para coberturas, estruturas ou fechamentos em projetos de arquitetura. A precisão dos desenhos e dos cortes permitiu ter maior controle sobre a fabricação de elementos construtivos. Este 
processo teve início na construção de um modelo paramétrico e terminou com uma máquina CNC que cortou as formas previamente modeladas no computador.

$O$ segundo método de FD investigado foi o aditivo, utilizando uma impressora 3D. A máquina FDM Stratasys que foi utilizada é capaz de criar protótipos rápidos adicionando camadas de 0,01 polegadas de espessura uma sobre a outra, cujo funcionamento se dá a partir de uma serpentina de ABS, um tipo de polímero armazenado em um cartucho que é introduzido na máquina. Um laser acoplado a um cabeçote que se move em x, y e z, derrete o ABS e prototipa um modelo.

A investigação contou com a prototipagem rápida de metade do edifício do Salão de Atos. Isso ocorreu por três motivos. Primeiramente por uma questão econômica, pois o ABS é um material muito caro. Por uma questão de tempo, pois o modelo demorou $8 \mathrm{~h} 56$ min para ser prototipado. $\mathrm{E}$ em terceiro lugar por limitações da máquina utilizada. Devido à esbeltez do pilar prototipado, a impressora criou um sistema de suporte em ABS cinza, que é facilmente destacável. Isso ocorreu por que o movimento do cabeçote da máquina poderia quebrar a peça.

Depois de impressa, as duas peças foram coladas com cola de precisão. Foi observado que o modelo não era autoportante, uma vez que só metade do pórtico que estrutura o edifício foi prototipado. Para que o modelo ficasse em pé foi introduzido um pequeno apoio em vidro. Importante citar que esse detalhe não anulou a importância do experimento, pois é possível observar no protótipo o desenvolvimento da curvatura e a mudança na espessura da casca, fatores que influenciam na plasticidade do conjunto e nos momentos estruturais do edifício.

O mesmo modelo digital foi submetido à fabricação de um modelo físico pelo processo de fabricação 2D usando uma cortadora a laser, como pode ser observado na Figura 5. Para a fabricação da casca e do pilar foi usado o comando Contour no Rhinoceros, capaz de "fatiar" camadas do edifício, transformando o tridimensional em bidimensional, preparando o modelo para ser cortado na cortadora a laser. Primeiramente uma folha de EVA $10 \mathrm{~mm}$ foi testada, porém, durante o corte foi possível detectar que quando o laser cortava peças muito delgadas o material derretia, e quando cortava as outras peças o laser produzia um chamuscado muito forte. Esse resultado inicial mostrou que devido a grande espessura da folha de EVA, a potência do laser teve que ser aumentada e a velocidade diminuída, o que produziu grande quantidade de calor, acarretando no derretimento de parte do material. A densidade do EVA dificultou a passagem do laser, gerando o chamuscado. Esse experimento deixa claro que nem todos os materiais são adequados para todos os tipos de fabricação digital, e que o laser interage com o mesmo material de formas diferentes, de acordo com as dimensões da peça cortada.

Para a segunda tentativa foi utilizada uma folha de spumapaper de $5 \mathrm{~mm}$ de espessura, esse material é composto por um polímero menos denso que o EVA com $4 \mathrm{~mm}$ de espessura, revestido por duas folhas de papel com $0,5 \mathrm{~mm}$ de espessura cada. Após 0 corte, que demorou 10 minutos e 38 segundos, foi averiguado que a parte central do material havia derretido e o papel saiu queimado, principalmente as peças de largura menor, após a análise das peças ficou claro que estas não serviriam para criar um modelo.

A terceira investigação ocorreu com o corte de folhas de papel tipo paraná revestido $2 \mathrm{~mm}$, por não ser um material vinílico como o EVA (Etil Vinil Acetato) o material não derrete. Não ocorreram imprevistos na fabricação com este material. O processo de corte demorou 6 minutos e 40 segundos, e ficou claro que essa seria a melhor opção para a fabricação o modelo, mesmo com algumas peças quebradas, devido a pequena espessura (1 $\mathrm{mm})$. 
Para a fabricação da viga foi utilizado o comando Unfold, no programa Rhinoceros, que é capaz de desdobrar a geometria 3D para 2D. A peça foi cortada em papel tipo triplex $2 \mathrm{~mm}$ em 40 segundos.

Este experimento mostrou que certos tipos de formas não funcionam em certos materiais, em escalas muito pequenas, ou em alguns tipos de FD, como é o caso do Salão de Atos Tiradentes, analisado por essa pesquisa e fabricado sobre o olhar de vários métodos de FD na mesma escala (1:200). Ficou claro que a prototipagem rápida, com impressora 3D, criou o modelo com maior precisão. Foi o único método, dentre os analisados, que conseguiu trabalhar com pequenas dimensões sem que houvesse nenhuma quebra do material. Era de se esperar que alguns materiais na fabricação $2 \mathrm{D}$, com a cortadora a laser, sofressem mais do que outros, principalmente pela escala pesquisada, portanto, se imagina que para uma a fabricação deste modelo em específico, do Salão de Atos, seria necessária a mudança para uma escala maior, o que aumentaria tamanho do modelo e consequentemente os custos com a fabricação digital.

Figura 5 - Prototipagem e fabricação digital do Salão de Atos Tiradentes

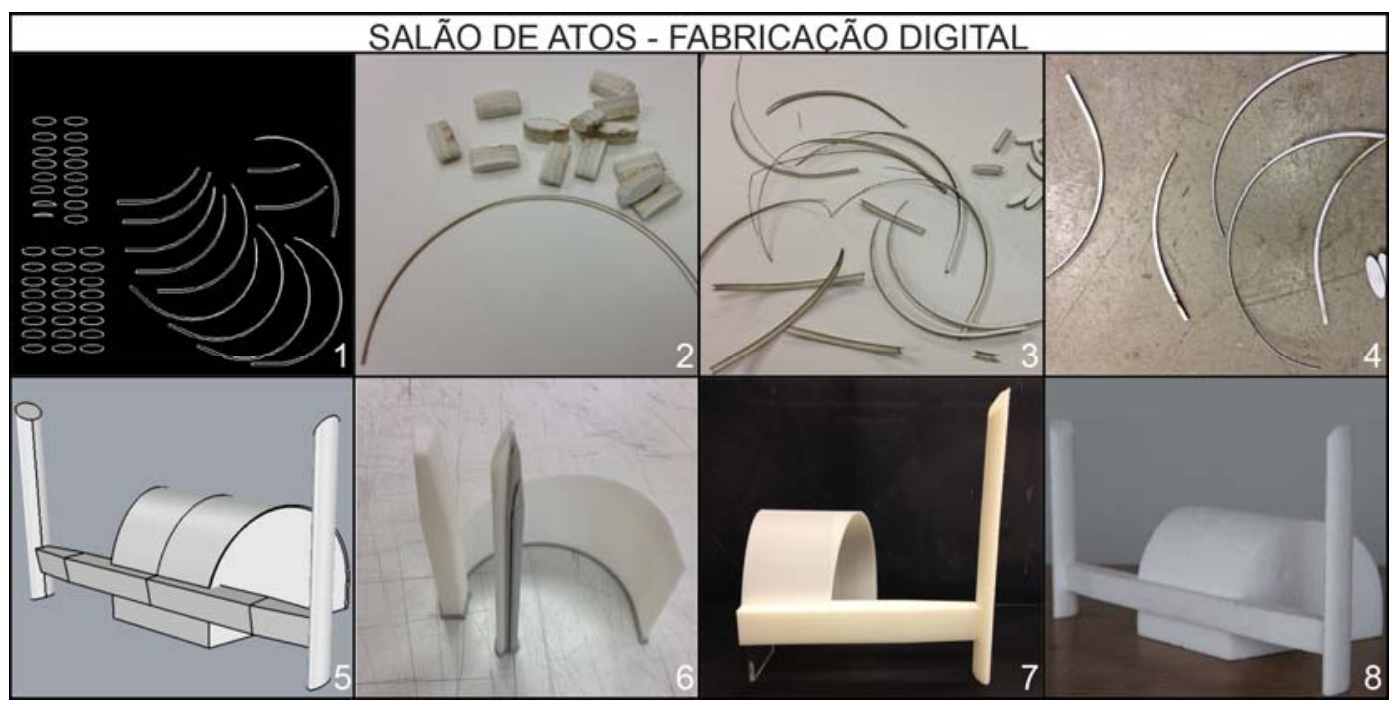

Fonte: Veiga e Florio, 2015

Na Figura 5, é possível observar diferentes tipos de fabricação digital para o Salão de Atos. (1) Mostra uma captura de tela das peças que serão cortadas na cortadora a laser, as elipses criariam o pilar do edifício e as curvas a casca de concreto. É possível observar em (2) que as peças elípticas estão chamuscadas e a extremidade de menor espessura derretida, devido a intensidade do laser sobre o EVA $10 \mathrm{~mm}$. Em (3) nota-se que o spumapaper de $5 \mathrm{~mm}$ ficou danificado com a parte central derretida, e os papeis das extremidades queimados. A última investigação utilizando a fabricação $2 \mathrm{D}$, mostra que mesmo com uma espessura de material menor, a peça cortada pelo laser ficou danificada (4).

A Figura 5 também mostra os métodos de fabricação 3D pelo qual o modelo digital do Salão de Atos (5) foi submetido. O material de cor cinza em (6), feito em um tipo de ABS de fácil remoção, foi adicionado pela impressora 3D para dar suporte à peça prototipada. Uma vez o suporte removido, as duas peças prototipadas, casca + viga e pilar, foram coladas entre si (7). Por fim o último método de FD utilizado foi a fabricação utilizando uma máquina CNC observado em (8). 


\section{ANÁLISE GEOMÉTRICA}

Mayer (2007) fez um estudo sistemático da geometria de parte da produção arquitetônica de Oscar Niemeyer, inclusive analisando um dos objetos de estudos desta pesquisa, 0 Auditório Simón Bolivar. Porém a autora utiliza como objeto de análise o projeto preliminar do Auditório, com proporções diferentes da construída. Existem grandes diferenças entre o projeto preliminar (dezembro/1987) e o executivo (março/1988). A autora embasou sua dissertação na busca por retângulos áureos, investigando diferentes proporções em planta e na fachada. Esta pesquisa tem como objetivo investigar o projeto executivo e analisar as diferentes geometrias que compõem a forma, o desenvolvimento da geometria da casca de concreto, analisando os raios de circunferências, as tangentes e os segmentos de reta.

Figura 6 - Confrontação de projetos e análises do Auditório Simón Bolivar

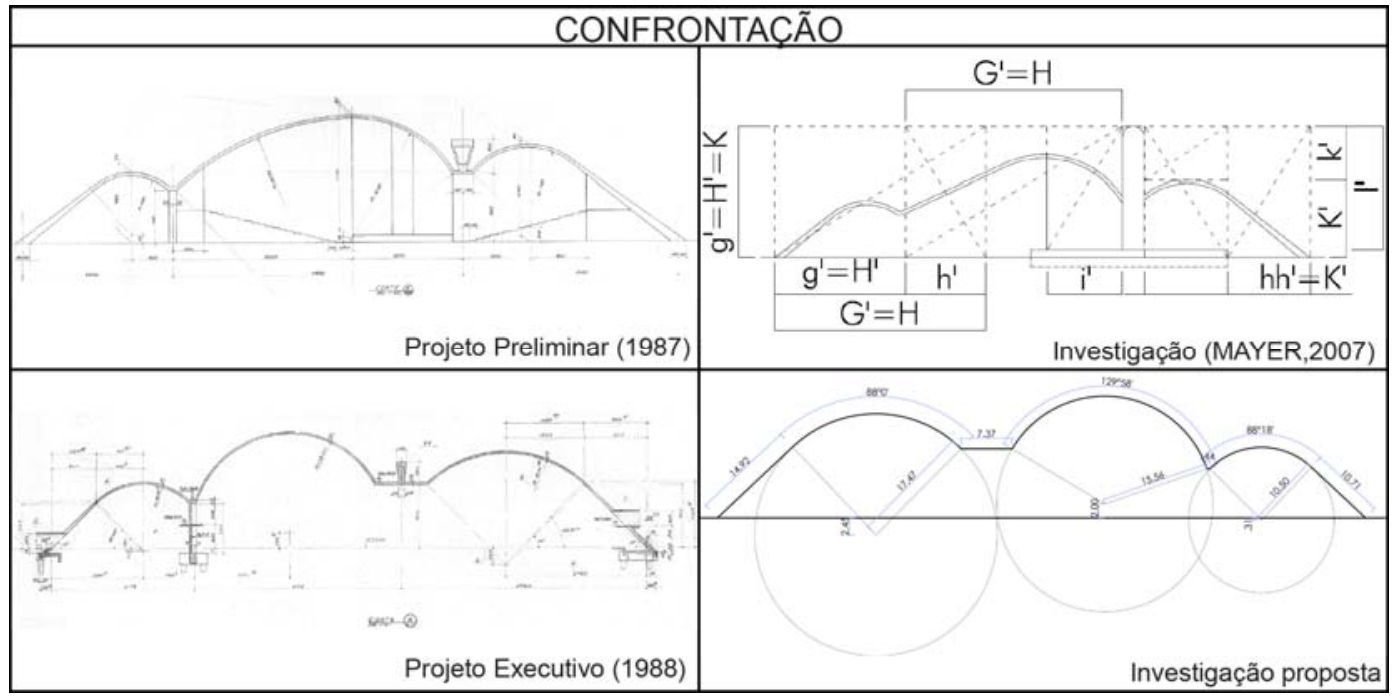

Fonte: Veiga e Florio, 2015

O primeiro estranhamento que ocorre ao observar o estudo preliminar (1987) é que a cobertura do espaço central é composta de dois arcos que se conectam um ao outro, mas que não expressam a pureza formal desejada pelo arquiteto.

Quando se observa o conjunto dos edifícios projetados por Oscar Niemeyer nota-se que raramente as coberturas curvilíneas são compostas por arcos consecutivos como esse, o que nos leva crer que a plasticidade desejada pelo arquiteto deriva de uma geometria de formas mais simples. Outra constatação é que provavelmente haveria certa dificuldade em proporcionar uma boa estabilidade estrutural e sua viabilização técnica.

Ao estudar a análise geométrica de Mayer (2007) constata-se que a autora não identifica as conexões existentes entre arcos de circunferência e suas tangentes. Seu estudo está mais focado na relação de proporção entre partes e todo, consequentemente identifica quadrados e retângulos áureos que demonstram boa proporção.

A partir do estudo do desenvolvimento da forma, isto é, a relação entre os vários elementos que compõem a forma, arcos de circunferências, tangentes e segmentos de reta, que compõem o vocabulário do arquiteto. É possível observar que a arquitetura de Oscar Niemeyer é resultado da conciliação entre formas simples. Neste projeto o arquiteto emprega uma sucessão de cascas de concreto estruturadas transversalmente por uma viga aporticadas. Esse tipo de abordagem estrutural reforça o fator inventivo do arquiteto, a casca de concreto, como utilizada em outras obras de sua autoria. É uma amálgama estrutural que une vigas e pilares em um conjunto só, um exoesqueleto estrutural, por sua 
vez a viga aporticada, com uma altura estrutural considerável, evidencia a estrutura e se contrapõem com a leveza e esbeltez da casca de concreto. Essas oposições entre reta e curva, casca e viga também aparecem no projeto do Salão de Atos e ficaram claras durante o estudo feito com a MP e a FD dos edifícios.

A Figura 7 mostra o estudo da geometria dos diversos elementos estruturantes do projeto e evidenciam os diferentes parâmetros usados na investigação, como o raio dos arcos de curvatura, as tangentes e seus pontos de apoio, a altura dos centros de circunferências e as alturas das lajes planas, formadas por segmentos de reta.

Figura 7 - Análise Geométrica do Auditório Simon Bolivar

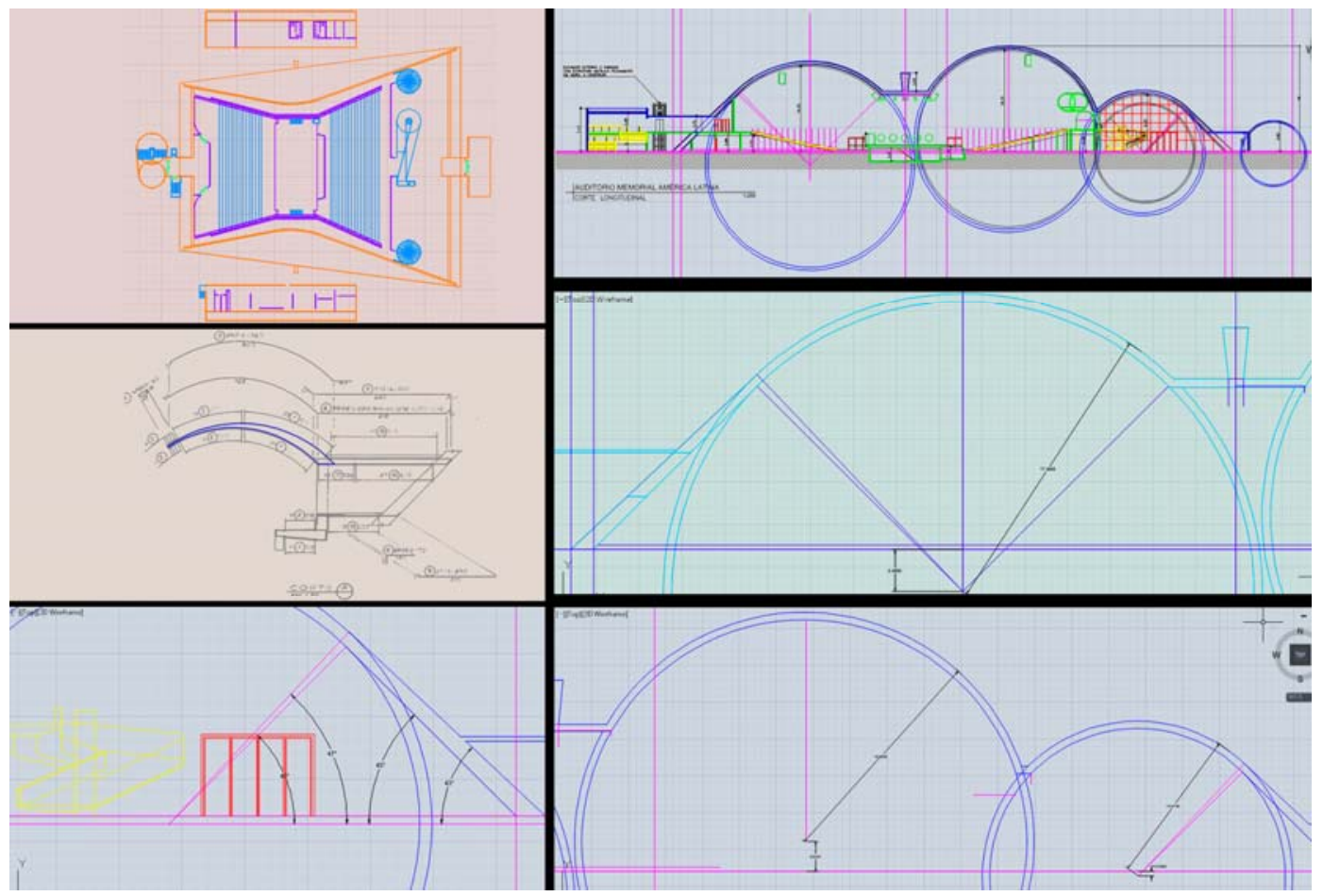

Fonte: Veiga e Florio, 2015

Nota-se que a forma dos edifícios concebidos por Niemeyer é criada a partir de uma curva ou uma sucessão de curvas longitudinalmente, por retas transversais que fazem com que a geometria resultante seja uma superfície regrada e de única curvatura. Esse aspecto construtivo faz com que a estrutura apresente maior plasticidade, melhor ritmo, harmonia, proporção e que possa ser construída mais facilmente.

\section{DISCUSSÃO E CONSIDERAÇÕES FINAIS}

Com a MD foi possível criar um algoritmo a partir de parâmetros pré-definidos e estabelecer relações entre as diferentes dimensões do projeto, criando novas relações de proporção da forma mantendo relações topológicas.

A MD foi importante para analisar a forma dos edifícios, o desenvolvimento da geometria e investigar as diferentes relações entre os diferentes elementos estruturantes. Foi possível alterar os parâmetros da geometria de modo a criar famílias de formas, que mantêm uma relação de similaridade entre cada versão. Após esta investigação ficou claro que a seleção da melhor forma depende dos conhecimentos do arquiteto, que vão além da forma e envolvem noções de estrutura, proporção e plasticidade. Além disso, a análise das formas 
geradas automaticamente pelos recursos computacionais contribuiu para a identificação de que muitas opções são pouco atraentes ou de difícil execução.

A fabricação de modelos físicos e de protótipos rápidos auxiliaram no entendimento da geometria dos edifícios. A experimentação de vários tipos de FD e de materiais possibilitou o entendimento das várias finalidades de cada tipo de modelo físico. O modelo físico fabricado com auxílio da fresadora possibilitou a compreensão da volumetria, a espacialidade no caso do Auditório Simón Bolivar e também as relações formais das diferentes curvaturas e do pórtico. A investigação através da prototipagem com a impressora 3D foi importante para o estudo da tectônica, pois foi possível fabricar espessuras milimétricas, com muita precisão. No caso do Salão de Atos foi possível observar a relação entre a espessura da casca de concreto e o resto da construção. Com os modelos fabricados em 2D usando diferentes materiais foi possível entender a relação entre os tipos de FD e os materiais usados, placas muito espessas ou feita de alguns materiais, quando submetidas a grandes potências do laser tendem a queimar ou derreter, para fabricação de objetos que possuam larguras muito pequenas, é aconselhável o uso de placas mais finas ou/e de materiais menos densos e não vinílicos.

Ao manusear um protótipo físico do edifício investigado, começa-se a entender melhor a tectônica da forma. Quando fabricado, seja em uma impressora 3D, em uma fresadora ou em uma cortadora a laser, o artefato físico resultante possibilita sua manipulação, promovendo o entendimento das diferentes características da matéria, como forma, dimensão, plasticidade e tectônica.

\section{AGRADECIMENTOS}

Os autores agradecem o apoio financeiro do CNPq e do Fundo MackPesquisa, e os funcionários do Laboratório de Prototipagem da Faculdade de Arquitetura e Urbanismo da Universidade Presbiteriana Mackenzie.

\section{REFERÊNCIAS}

BRUSCATO, U. M.; ALVARADO. R. G. Muro - pixel: exploración digital de un sistema constructivo de placas entrelazadas. In: CONGRESSO DA SOCIEDADE IBEROAMERICANA DE GRÁFICA DIGITAL, 14, SIGRADI 2010, Bogotá. Anais... Bogotá, Colombia: UNIVERSIDAD DE LOS ANDES, 2010, p. 205-208.

BUENO, E.; BARRERA, C. El Scripting como estrategia de diseño: una experiencia pedagógica: Scripting as a strategy for the design: one pedagogical experience. In: CONGRESSO DA SOCIEDADE IBEROAMERICANA DE GRÁFICA DIGITAL, 12, SIGRADI 2008, La Habana. Anais... La Habana, Cuba, 2008, p. 549-553.

CELANI, G. Enseñando diseño generativo: una experiencia didáctica. In: CONGRESSO DA SOCIEDADE IBEROAMERICANA DE GRÁFICA DIGITAL, 13, SIGRADI 2009, São Paulo. Anais... 2009, São Paulo, Brasil: UPM, 2009, p. 162-165.

CHIARELLA, M. Superficies paramétricas y arquitectura: Conceptos, ideación y desarrollo. In: CONGRESSO DA SOCIEDADE IBEROAMERICANA DE GRÁFICA DIGITAL, 8, SIGRADI 2004, Porto Alegre. Anais... Porto Alegre, Brasil: UNISINOS, 2004, p. 393-395.

FLORIO, W.; TAGLIARI, A. O uso da cortadora a laser na fabricação digital de maquetes físicas. In: CONGRESSO DA SOCIEDADE IBEROAMERICANA DE GRÁFICA DIGITAL, 12, SIGRADI 2008, La Habana. Anais... La Habana, Cuba, 2008, p. 256-263.

HANNA, S.; TURNER, A. Teaching parametric design in code and construction: Enseñando Diseño paramétrico en código y construcción. In: CONGRESSO DA SOCIEDADE IBEROAMERICANA DE 
GRÁFICA DIGITAL, 10, SIGRADI 2006, Santiago de Chile. Anais... Santiago de Chile, Chile, 2006, p. $158-161$.

HARDY, S. Parametricism: Student Performance Criteria (SPC). In: ASSOCIATION FOR COMPUTER AIDED IN ARCHITECTURE, ACADIA 2011, Lincoln. Anais... Lincoln: University of Nebraska, 2011, P. 12-15.

HERNANDEZ, C. R. B. Parametric Gaudi. In: CONGRESSO DA SOCIEDADE IBEROAMERICANA DE GRÁFICA DIGITAL, 8, SIGRADI 2004, Porto Alegre. Anais... Porto Alegre, Brasil: UNISINOS, 2004, p. 213-215.

HERRERA, P. C. Patrones y convenciones en el uso de Rhinoscripting. In: CONGRESSO DA SOCIEDADE IBEROAMERICANA DE GRÁFICA DIGITAL, 13, SIGRADI 2009, São Paulo. Anais... São Paulo, Brazil: UPM, 2009, p. 340-342.

HUDSON, R. Strategies for parametric design in architecture. An application of practice led research. Thesis Department of Architecture and Civil Engineering, University of Bath, 2010. 274p.

KOLAREVIC, B. Architecture in the digital age: Design and manufacturing. Londres: Taylor \& Francis, 2003. 320p.

MAYER, R. A linguagem de Oscar Niemeyer. Dissertação (Mestrado em Arquitetura). Programa de Pesquisa e Pós-Graduação em Arquitetura da Universidade Federal do Rio Grande do Sul. 2003. $197 p$.

MONEDERO, J. Parametric design: a review and some experiences. Automation in Construction, v. 9, n. 4, p. 369-377, 2000.

OXMAN, R.Theory and design in the first digital age. Design Studies, V. 27, n. 3, 2006. 37p.

POTTMANN, H.; ASPERL, A.; HOFER, M.; KILIAN, A. Architectural Geometry. Exton: Bentley Institute Press, 2007. 724p.

ROGERS, D. F. An Introduction to NURBS: With Historical Perspective. San Francisco: Morgan Kaufmann Publishers, 2001.

SASS, L. Reconstructing Palladio's Villa: An Analysis of Palladio's Villa Design and Construction Process. Thesis (Doctorate of Architecture: Design \& Computation), Department of Architecture, Massachussets Institue of Technology, Cambridge, 2000.

SASS, L; OXMAN. R. Materializing design: the implications of rapid prototyping in digital design. Design Studies, V. 27, n. 3, 2006. 37p.

SCHODEK, D. et al. Digital Design and Manufacturing: CAD/CAM Applications in Architecture and Design. Hoboken: John Wiley \& Sons, 2005. 369p.

SCHUMACHER, P. The Autopeiesis of Architecture: A New Framework for Architecture, Volume I. Chinchester: John Wiley, 2011. 481p.

TAGLIARI, A.; FLORIO, W. Fabricação Digital de Superfícies: Aplicações da Modelagem Paramétrica na Criação de Ornamentos na Arquitetura Contemporânea. In: CONGRESSO DA SOCIEDADE IBEROAMERICANA DE GRÁFICA DIGITAL, 13, SIGRADI 2009, São Paulo. Anais... 2009, São Paulo, Brasil: UPM, 2009, p. 77-79.

TERZIDIS, K. Algorithmic Architecture. Oxford: Elsevier, 2006. 177p.

WOODBURY, R. Elements of Parametric Design. Abingdon, Oxon: Routledge, 2010. 300p. 